\title{
Retinal Neuroblastoma
}

National Cancer Institute

\section{Source}

National Cancer Institute. Retinal Neuroblastoma. NCI Thesaurus. Code C6956.

A neuroblastoma arising from the retina. 